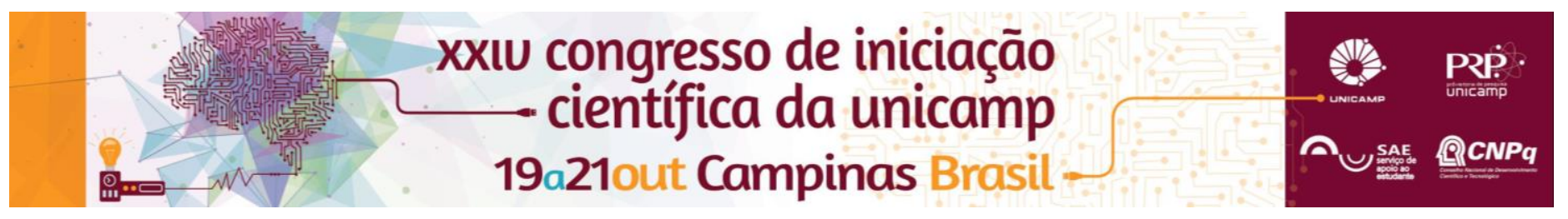

\title{
A INFLUÊNCIA DO TREINADOR EM ATLETAS DE NATAÇÃO
}

\author{
Milena S. R. Barnabe*; João G. C. Chiminazzo; Vinicius N. Soares; Paula T. Fernandes
}

\begin{abstract}
Resumo
A prática esportiva está presente no cotidiano das pessoas, o que contribui para que crianças e adolescentes se interessem por diferentes modalidades. Neste sentido, acreditamos que a relação treinador-atleta é importante para a permanência dos praticantes nos programas de treinamento, o que se contrapõe ao fato de que na natação existem poucas evidências científicas acerca deste tema. A partir disso, o objetivo deste estudo foi descrever as percepções dos atletas sobre as condutas dos treinadores e as percepções dos treinadores sobre as próprias condutas. Para isso, avaliamos 24 nadadores e 3 treinadores, com os seguintes instrumentos: Escala de Comportamento do Treinador Visão Atleta (ECT-A) e Escala de Comportamento de Treinadores Desportivos - Versão Treinadores (ECT-T). Os resultados mostraram que que as médias das respostas dos treinadores e dos atletas aos questionários quanto aos aspectos psicológicos foram parecidas. A partir disso, pode-se inferir que os treinadores investigados apresentaram preocupação com a formação abrangente (i.e., que inclui aspectos técnicos, físicos e psicológicos) dos atletas.
\end{abstract}

Palavras-chave: Psicologia do Esporte, Relação Treinador-Atleta, Natação.

\section{Introdução}

A relação treinador-atleta pode ser determinante para que $o$ atleta permaneça e se desenvolva na modalidade desportiva (HOSHINO, 2007). Porém, o relacionamento inadequado pode ser prejudicial aos praticantes, acarretando em abandono ou término precoce da carreira desportiva (BRANDÃO, 2000). Tendo em vista a importância dessa temática, nosso objetivo foi avaliar e descrever as percepções dos atletas sobre as condutas dos treinadores e a percepção dos treinadores sobre as próprias condutas.

\section{Materiais e Métodos}

Foram avaliados 27 participantes, sendo 24 atletas e 3 treinadores. Dentre os atletas, 10 homens e 14 mulheres, com média de idade de 15 anos $( \pm 1,20), 4$ anos $( \pm 2,82)$ de experiência, e com vínculo de 2 anos $( \pm 1,65)$ com o treinador. Os treinadores tinham em média 30 anos $( \pm 3,21)$, e experiência profissional de 5 anos $( \pm 1,53)$.

Ao final do treinamento, os participantes responderam aos instrumentos: ficha de identificação, Questionário Escala de Comportamento do Treinador - Visão Atleta (ECT-A) ou a Escala de Comportamento de Treinadores Desportivos - Versão Treinadores (ECT-T).

Para analisar os dados, inicialmente delimitamos as questões dos instrumentos que eram correspondentes, e, depois, quantificamos e comparamos as respostas para comparar condutas dos treinadores com as percepções dos atletas.

\section{Resultados e Discussões}

A partir de duas questões de cada dimensão do comportamento do treinador, foi feito um gráfico representado pela figura 1 , mostrando que houve uma correlação entre as respostas dos treinadores e dos atletas. Pode-se perceber que a percepção dos atletas em relação ao comportamento do treinador e as respostas dos técnicos sobre seus próprios comportamentos foram mais próximos nos aspectos psicológicos em relação às outras duas dimensões. Além disso, na maioria das questões, foi possível observar que os atletas tem uma visão mais positiva do comportamento do treinador do que os próprios técnicos.

A interpretação do treinador sobre suas próprias atitudes e o que ele realmente transmite, reforçam o que Brandão (2010) afirma sobre a comunicação ser um fator crucial para estimular, aumentar a autoestima e despertar o gosto do atleta pela modalidade.

Figura 1. Comparação entre as respostas dos treinadores e atletas

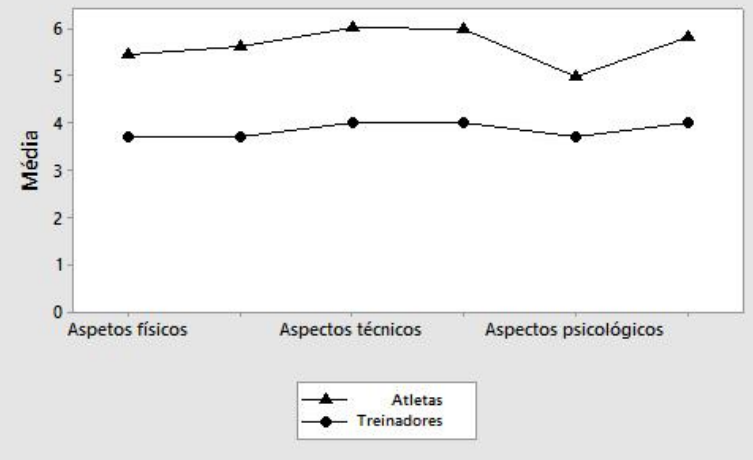

\section{Conclusões}

A partir do estudo, concluiu-se que os treinadores demonstraram empenho em promover formação abrangente, preocupando-se não somente com a especificidade da natação, mas também com questões psicológicas, o que é confirmado pelos atletas.

${ }^{1}$ Hoshino, E. F.; Sonoo, C. N.; Vieira, L. L. R. da Educação Física/UEM 2007,18;1; 77-83.

${ }^{2}$ Brandão, M. R. F.; Carchan, D. Motricidade, 2000, 6;1; 55-69.

${ }^{3}$ Brandão, M.R.F; Carchan,D. Motricidade, 2010, 6; 1; 53-69. 